\title{
Pesca do apaiari, Astronotus ocellatus (Agassiz, 1831), e perfil socioeconômico dos pescadores artesanais de uma região da Amazônia brasileira \\ Apaiari fishing, Astronotus ocellatus (Agassiz, 1831), and socioeconomic profile of artisanal fishermen in a region of the Brazilian Amazon
}

\author{
Márcia Dayane Vilhena Daaddy!, Cesar Santos", Rúbia Maielli Lima Brandão"II, \\ Renan Diego Amanajás III, Ana Beatriz Nunes Ribeiro ${ }^{I V}$ \\ 'Universidade Federal do Amapá. Macapá, Amapá, Brasil \\ "Empresa Brasileira de Pesquisa Agropecuária. Macapá, Amapá, Brasil \\ IIIInstituto Nacional de Pesquisas da Amazônia. Manaus, Amazonas, Brasil \\ Iv Universidade do Estado do Amapá. Macapá, Amapá, Brasil
}

\begin{abstract}
Resumo: A pesca artesanal é uma importante atividade econômica e de subsistência para as populações tradicionais da região amazônica. O objetivo deste estudo foi caracterizar a pesca do apaiari, Astronotus ocellatus (Agassiz, 1831), e o perfil socioeconômico dos pescadores artesanais da região dos lagos de Pracuúba, Amapá. De maio a agosto de 2011, foram realizadas entrevistas, através de formulários padronizados, com pescadores selecionados por meio do método "bola de neve', com idade acima de 18 anos. Dos 68 pescadores selecionados, 55 eram do sexo masculino e 13 do feminino. A partir dos resultados, observou-se que os pescadores possuem um amplo conhecimento da atividade na região, incluindo a pesca do apaiari. Tanto a vida social quanto a econômica desta população dependem totalmente da pesca artesanal.
\end{abstract}

Palavras-chave: Pesca artesanal. Socioeconomia. Etnobiologia. Conhecimento tradicional.

\begin{abstract}
The artisanal fishery is an important economic and subsistence activity among traditional populations in the Amazon Region. Therefore, the aim of this study was to characterize the fishery of apaiari, Astronotus ocellatus (Agassiz, 1831), and to present a socioeconomic profile of artisanal fishermen in the region lakes of Pracuúba, Amapá, Brazil. From May to August 2011 interviews were conducted using standardized forms with fishermen selected by "snowball" method and aged above 18 years old. A total of 68 fishing workers were interviewed, of which 55 were men and 13 women. It was possible to observe that fishing workers have a wide knowledge of fishery in the Region, including apaiari fishery, and that social and economic lives of the Pracuúba population depend totally of the artisanal fishery.
\end{abstract}

Keywords: Artisanal fishery. Socioeconomics. Ethnobiology. Traditional knowledge.

DAADDY, Márcia Dayane Vilhena; SANTOS, Cesar; BRANDÃO, Rúbia Maielli Lima; AMANAJÁS, Renan Diego; RIBEIRO, Ana Beatriz Nunes. Pesca do apaiari, Astronotus ocellatus (Agassiz, 1831), e perfil socioeconômico dos pescadores artesanais de uma região da Amazônia brasileira. Boletim do Museu Paraense Emílio Goeldi. Ciências Humanas, v. 11, n. 2, p. 363-378, maio-ago. 2016. DOI: http://dx.doi. org/10.1590/1981.81222016000200002.

Autora para correspondência: Márcia Dayane Vilhena Daaddy. Universidade Federal do Amapá. Rodovia Juscelino Kubtscheck, s/n, km 02 Jardim Marco Zero. Macapá, AP, Brasil. CEP 68903-419 (mdayvilhena@gmail.com).

Recebido em 09/12/2014

Aprovado em 01/06/2016

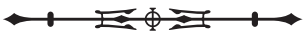




\section{INTRODUÇÃO}

A pesca artesanal na Amazônia constitui uma tradição arraigada ao hábito de vida das populações ribeirinhas (Santos, G.; Santos, A., 2005, p. 167). Sua importância, entre outros motivos, não está alinhada somente à produção de alimentos, mas também às diferentes estratégias e aos comportamentos associados ao uso do recurso pesqueiro (Freitas; Rivas, 2006, p. 30). Assim, mais de 300 mil pescadores têm sua fonte de renda na atividade, o que culminou na produção aproximada de 137 mil toneladas de pescados, e 55\% de toda a produção em águas continentais do país no ano de 2011 (MPA, 2010, p. 35; 2011, p. 22-29).

A compreensão dos modos de operação, da detecção dos peixes e das formas de captura, da interação da sazonalidade ambiental com a dinâmica populacional das espécies, e a relação destas com os pescadores, ditam certa complexidade na análise da atividade por toda a região, visto que a ligação entre o homem e a natureza demonstra que as comunidades pesqueiras desenvolveram modos de vida específicos, visando à adaptação às variações do ecossistema e buscando formas de transmissão dos conhecimentos adquiridos ao longo das gerações, específicos de cada comunidade pesqueira (Mérona, 1993, p. 164; Berkes et al., 2000, p. 1252; Barthem; Fabré, 2004, p. 48).

De acordo com Ramires et al. (2012, p. 232), a busca por informações junto a estas comunidades fornece importantes dados para a composição da estatística da pesca no país, tanto em relação à biologia pesqueira quanto à socioeconomia, muito embora sejam difusas. Para que medidas para o manejo pesqueiro possam efetivamente ser implementadas, contemplando os recursos pesqueiros e as comunidades que deles dependem, é necessário conhecer as características da atividade ao longo do território, como quais são as espécies mais exploradas, as estratégias de pesca empregadas e a realidade socioeconômica dos pescadores, tendo como um dos pilares básicos a percepção desses atores sociais (Silvano, 2004, p. 189; Begossi, 2010, p. 17). Para a região amazônica, apesar de a pesca ter forte expressão alimentar, cultural e econômica, a carência de informações dessa natureza tem impossibilitado a execução adequada da gestão da atividade (Inomata; Freitas, 2015, p. 80).

O estado do Amapá, localizado na região geográfica da bacia amazônica, tem na pesca de caráter artesanal, praticada nas águas interiores, pouca competitividade, se comparada àquela praticada na região costeira e estuarina por embarcações de outros estados (Silva; Dias, 2010, p. 44). A região lacustre do município do Pracuúba, importante polo pesqueiro amapaense, tem na exploração de espécies como o aracu (Schizodon fasciatus), o tucunaré (Cichla sp.), a traíra (Hoplias malabaricus) e o apaiari (Astronotus ocellatus) uma significante fonte de renda (Silva, L.; Silva, S., 2006, p. 187). Dados reportam ser a espécie $A$. ocellatus, endêmica da bacia amazônica, uma das mais capturadas no estado do Amapá, com 597 toneladas produzidas em 2007 (IBAMA, 2007, p. 65). Todavia, informações a respeito da pesca desta espécie na região são extremamente escassas, o que pode estar incorrendo na gestão inadequada das pescarias. Embora estratégica e economicamente importante, a pesca de $A$. ocellatus na região é pouco explorada sob a perspectiva do conhecimento tradicional dos pescadores e, além disso, é pouco conhecida a situação social deste grupo, dificultando a implementação de políticas públicas voltadas ao setor pesqueiro.

Diante do exposto, este trabalho teve por objetivo caracterizar a pesca da espécie Astronotus ocellatus, a partir da percepção dos pescadores da região lacustre do município de Pracuúba, no estado do Amapá, bem como avaliar a situação socioeconômica desses pescadores, com o intuito de gerar informações que possibilitem a melhor gestão da cadeia produtiva da pesca na região.

\section{MATERIAL E MÉTODOS}

\section{ÁREA DE ESTUDO}

O município de Pracuúba está localizado no estado do Amapá e faz parte da Amazônia brasileira (Figura 1). 


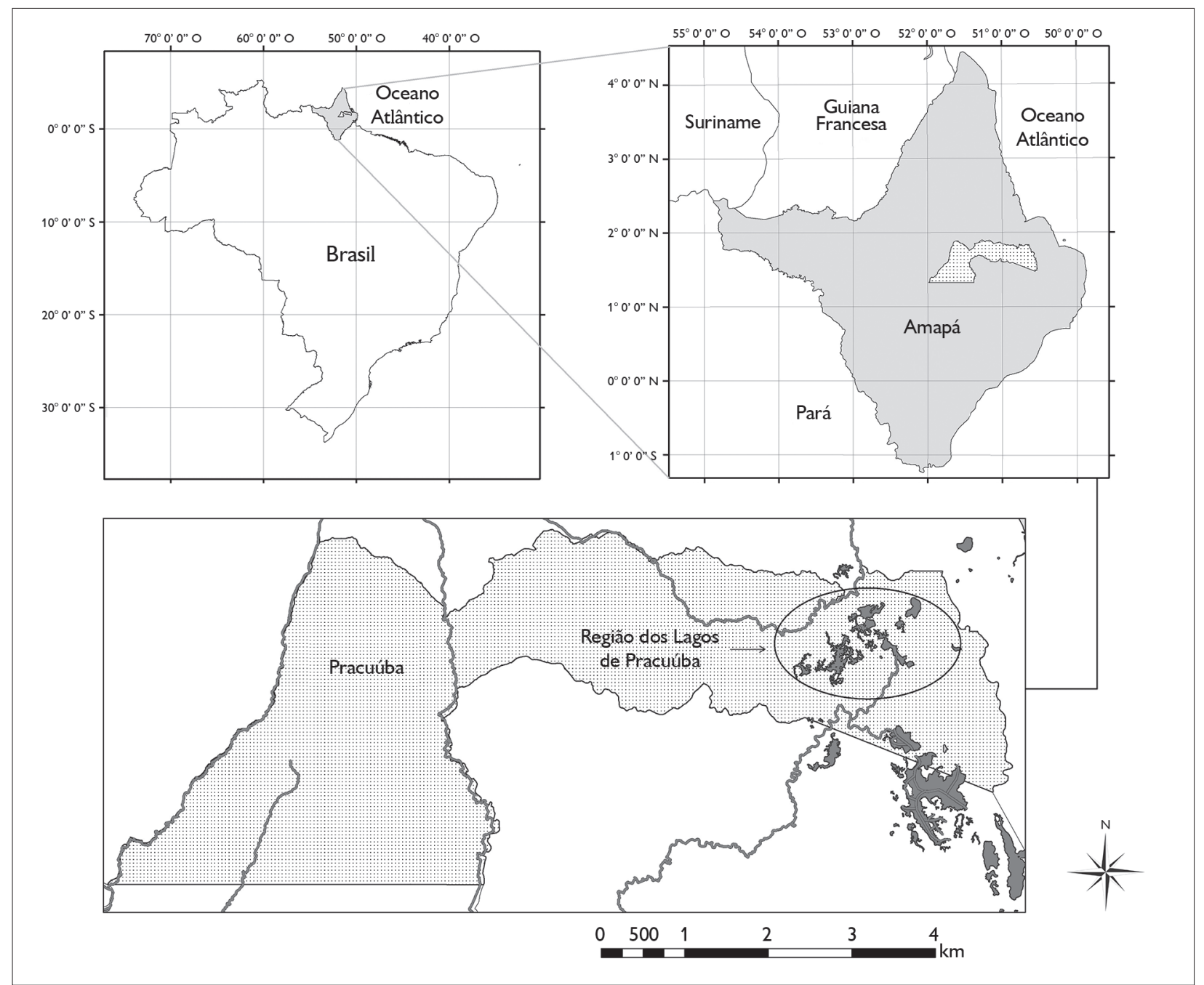

Figura 1. Mapa de localização do município de Pracuúba, estado do Amapá, Amazônia, Brasil.

Possui uma área de 4.957 km², onde estão inseridas duas unidades de conservação ambiental: a Floresta Nacional do Amapá e a Floresta Estadual do Amapá. Sua população é de 3.793 pessoas (IBGE, 2010), divididas entre as seguintes comunidades: Pracuúba, Breu, Cujubim, Flexal, Pernambuco, Porto Franco, São Miguel e Tucunaré. A região apresenta clima tipicamente amazônico - quente e úmido -, estando situada em área inundável e sendo regulada pelo regime pluviométrico (Rabelo et al., 2006, p. 71).

A sazonalidade dos períodos de chuva na região faz com que os vastos campos naturais sejam inundados durante o primeiro semestre do ano, para, posteriormente, secarem pela ausência de chuvas durante parte do segundo semestre. Essa dinâmica sazonal evidencia ainda mais os grandes lagos que compõem a região, e a potencializa como grande produtora de pescado (Rabelo et al., 2006, p. 70-71).

As principais atividades econômicas desenvolvidas na região são: extrativismo vegetal; agricultura de subsistência; pecuária e pesca, sendo esta última de grande relevância para a economia local. Segundo informações da Superintendência Estadual de Aquicultura 
e Pesca (SEPAq), 200 pescadores são associados à Colônia Z11 (Silva, L.; Silva, S., 2006, p. 176), porém se estima que esse número seja maior, pois muitos pescadores não estão vinculados à Colônia.

\section{COLETA DE DADOS}

Antes de iniciar o levantamento de dados, fez-se uma visita exploratória, em abril de 2011, com o intuito de conhecer melhor a região e, através de conversa informal, identificar pescadores experientes que pudessem auxiliar a equipe de pesquisa no início do estudo.

A pesquisa foi realizada de maio a agosto de 2011, e consistiu em entrevistas, feitas por meio de perguntas semiestruturadas, organizadas na mesma ordem para todos os entrevistados (Silvano, 2004, p. 195). Foram selecionados pescadores com idades acima de 18 anos pelo método snow ball ou 'bola de neve', preconizado por Bailey (1982, p. 96) e Silvano (2004, p. 197), o qual consiste em um pescador indicar o outro, e assim sucessivamente. Desta forma, seria possível alcançar o maior número de participantes.

Durante a abordagem, a equipe se apresentava, informando seus nomes, instituição e explicava os principais pontos da pesquisa. Caso o pescador aceitasse participar, era feita a leitura do "termo de consentimento livre e esclarecido", que elucidava ao entrevistado sobre os objetivos do trabalho e o uso das informações repassadas por ele, assegurando que o mesmo não seria identificado na publicação dos resultados. Através de assinatura ou impressão digital, para os que não assinavam o nome, todos autorizaram as entrevistas e o uso das informações nas condições estabelecidas no termo. Além disso, algumas entrevistas foram gravadas em áudio, quando autorizadas, para que questões importantes pudessem ser registradas.

Sobre a socioeconomia, foram obtidas as seguintes informações: nome, sexo, idade, local de nascimento, comunidade onde mora, tempo de moradia na região, estado civil, escolaridade, número de filhos, tempo em que pratica a atividade de pesca, número de membros da família que também atuam na pesca, dias de pescaria, acompanhantes no trabalho, tipo de embarcação, espécies que costuma pescar, nome dos locais onde pratica a atividade, conservação e comercialização do pescado, renda mensal proveniente desta ocupação, prática de outra atividade além da pesca, renda proveniente dessa prática, dependentes da renda mensal e vínculo com a colônia de pescadores. Além das perguntas semiestruturadas, foram feitas observações in loco sobre o papel das mulheres naquele grupo e também questões sobre moradia, saneamento básico, energia elétrica, entre outras.

A respeito da pesca do apaiari, inicialmente, foi apresentada uma fotografia da espécie para os pescadores, requerendo seu próprio reconhecimento do peixe, sem que houvesse interferência do entrevistador para tal informação. Em seguida, foram feitas perguntas sobre os melhores locais, a melhor época para captura, os apetrechos de pesca mais utilizados, tamanho de captura, quantidade por pescaria, preço de venda, formas de consumo, espécies acompanhantes na pescaria, além de questões sobre a situação do estoque da espécie nos lagos da região.

Os dados das entrevistas foram organizados em planilhas computadorizadas para análise descritiva, e as gravações foram transcritas utilizando-se o programa Scribe.

\section{RESULTADOS}

\section{SOCIOECONOMIA DOS PESCADORES}

\section{ARTESANAIS}

Foram entrevistados 68 pescadores e, desse total, 80,9\% são do gênero masculino. A idade média dos entrevistados foi de 40,7 anos, sendo que o pescador mais jovem tinha 21 anos e o mais velho, 79 anos. Quanto à naturalidade, a maioria, 72\%, nasceu em Pracuúba, e 28\% em outras cidades dos estados do Amapá e do Pará. Destes últimos, o tempo de residência no município variou de três meses a 37 anos.

Apesar de a sede possuir uma escola estadual e uma municipal, e de todas as comunidades possuírem uma escola municipal, foi verificada baixa escolaridade

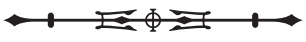


entre todos os entrevistados, sendo que 5,9\% não são alfabetizados e 61,8\% não concluíram o ensino fundamental.

Com relação à estrutura familiar, observou-se que $63 \%$ dos pescadores são casados no civil ou têm união estável e, desse total, apenas 10,3\% não possuem filhos. A maioria das famílias vive em casas típicas da região, de madeira e coberta por telhas de amianto (Figura 2), as quais, de forma geral, são o local onde o pescado é comercializado. A Tabela 1 apresenta a caracterização geral dos pescadores de Pracuúba.

As moradias dos pescadores não apresentam infraestrutura de saneamento básico. Não possuem água tratada pela Companhia de Água e Esgoto do Amapá (CAESA). Desse modo, a água utilizada pela população é proveniente de poços escavados nos quintais de suas residências. Em contrapartida, todas as comunidades do município, incluindo a sede, possuem energia elétrica fornecida pela Companhia de Eletricidade do Amapá (CEA).

No que corresponde à atividade pesqueira, todos os entrevistados declararam ser pescadores artesanais profissionais, dependendo diretamente da pesca, tanto para sua subsistência quanto como principal fonte de renda. Destes, $79 \%$ têm de dez a 70 anos praticando a atividade e, apesar de todos se declararem pescadores artesanais, 20\% não são cadastrados na Colônia Z11. Portanto, não possuem a carteira de pescador artesanal profissional e não recebem o Seguro Defeso. Na Tabela 2 estão descritos os dados socioeconômicos referentes à pesca na região.

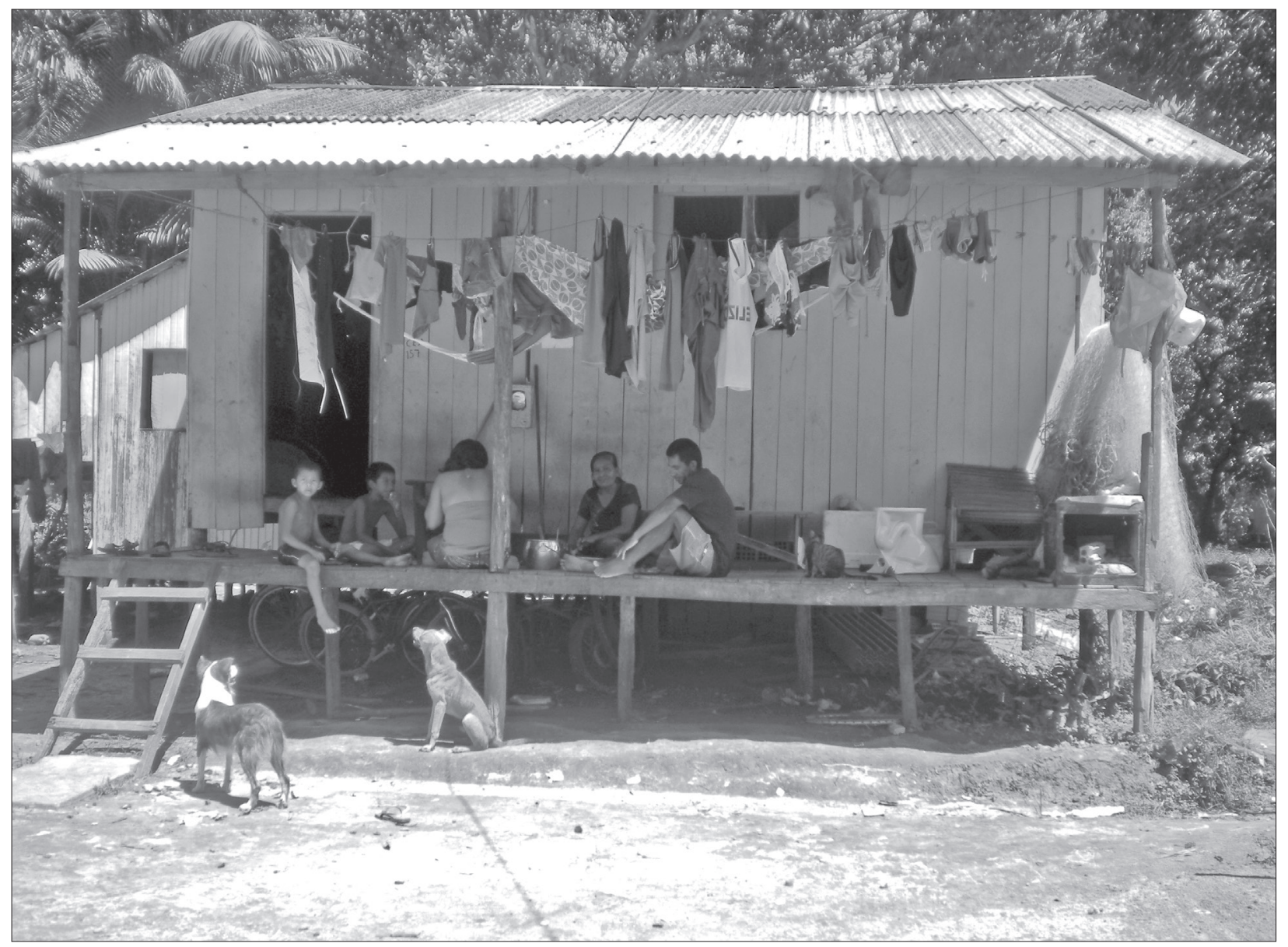

Figura 2. Residência dos pescadores artesanais do município de Pracuúba, estado do Amapá, Amazônia, Brasil. Foto: Márcia Daaddy.

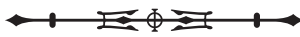


A maioria dos entrevistados $(80,9 \%)$ declarou ter uma ou mais pessoas da família que trabalha com atividade pesqueira. Sobre a coletividade nas pescarias, $72 \%$ afirmaram pescar com duas ou três pessoas, sendo os acompanhantes, geralmente, membros de sua família - por exemplo, marido acompanhado da esposa, o pai acompanhado do filho - ou então amigo de relação próxima.

Tabela 1. Informações socioeconômicas dos pescadores. Legenda: $\mathrm{n}=$ número de entrevistados.

\begin{tabular}{|c|c|c|c|}
\hline & Variável & $n$ & $\%$ \\
\hline \multirow{2}{*}{ Gênero } & Masculino & 55 & 80,9 \\
\hline & Feminino & 13 & 19,1 \\
\hline \multirow{6}{*}{ Idade (anos) } & 20 a 29 & 15 & 22,1 \\
\hline & 30 a 39 & 21 & 30,9 \\
\hline & 40 a 49 & 14 & 20,6 \\
\hline & 50 a 59 & 12 & 17,6 \\
\hline & 60 a 69 & 5 & 7,4 \\
\hline & 70 a 79 & 1 & 1,4 \\
\hline \multirow{3}{*}{ Naturalidade } & Pracuúba & 49 & 72,0 \\
\hline & Outro município (Amapá) & 15 & 22,1 \\
\hline & Outro município (Pará) & 4 & 5,9 \\
\hline \multirow{5}{*}{ Escolaridade } & Não alfabetizado & 4 & 5,9 \\
\hline & Ensino fundamental incompleto & 42 & 61,8 \\
\hline & Ensino fundamental completo & 2 & 2,9 \\
\hline & Ensino médio incompleto & 16 & 23,5 \\
\hline & Ensino médio completo & 4 & 5,9 \\
\hline \multirow{4}{*}{ Estado civil } & Casado/união estável & 43 & 63,3 \\
\hline & Solteiro & 17 & 25,0 \\
\hline & Separado & 6 & 8,8 \\
\hline & Viúvo & 2 & 2,9 \\
\hline \multirow{6}{*}{ Filhos } & Não tem & 7 & 10,3 \\
\hline & 1 a 3 & 20 & 29,4 \\
\hline & 4 a 6 & 25 & 36,8 \\
\hline & 7 a9 & 7 & 10,3 \\
\hline & 10 a 12 & 8 & 11,8 \\
\hline & 13 a 15 & 1 & 1,4 \\
\hline \multirow{2}{*}{ Habitação } & Madeira & 65 & 95,5 \\
\hline & Alvenaria & 3 & 4,5 \\
\hline
\end{tabular}

Tabela 2. Informações socioeconômicas referentes à atividade de pesca. Legendas: $\mathrm{n}=$ número de entrevistados; * = salário mínimo em 2011: R\$ 545,00; $*$ ** = outras atividades: vaqueiro, servente, pedreiro, vigilante noturno, capinador, vendedor de açaí.

\begin{tabular}{|c|c|c|c|}
\hline & & \multicolumn{2}{|c|}{ (Continua) } \\
\hline & Variável & $\mathrm{n}$ & $\%$ \\
\hline \multirow{7}{*}{$\begin{array}{c}\text { Tempo como } \\
\text { pescador artesanal } \\
\text { (anos) }\end{array}$} & $<10$ & 14 & 21 \\
\hline & 10 a 19 & 16 & 23,5 \\
\hline & 20 a 29 & 17 & 25 \\
\hline & 30 a 39 & 9 & 13,2 \\
\hline & 40 a 49 & 9 & 13,2 \\
\hline & 50 a 59 & 2 & 2,9 \\
\hline & 60 a 69 & 1 & 1,2 \\
\hline \multirow{5}{*}{$\begin{array}{l}\text { Membros da família } \\
\text { que trabalham } \\
\text { com a pesca }\end{array}$} & Apenas o entrevistado & 13 & 19,1 \\
\hline & $1 \mathrm{a} 2$ & 36 & 53 \\
\hline & 3 a 4 & 15 & 22,1 \\
\hline & 5 a 6 & 3 & 4,4 \\
\hline & $>6$ & 1 & 1,4 \\
\hline \multirow{2}{*}{$\begin{array}{l}\text { Pescadores } \\
\text { embarcados }\end{array}$} & Sozinho & 19 & 28 \\
\hline & 2 a 3 & 49 & 72 \\
\hline \multirow{3}{*}{$\begin{array}{l}\text { Finalidade } \\
\text { da pesca }\end{array}$} & Subsistência & 4 & 5,9 \\
\hline & Comercialização & 10 & 14,7 \\
\hline & $\begin{array}{l}\text { Subsistência e } \\
\text { comercialização }\end{array}$ & 54 & 79,4 \\
\hline \multirow{2}{*}{$\begin{array}{c}\text { Colônia de } \\
\text { pescadores Z-11 }\end{array}$} & Não cadastrados & 14 & 20,6 \\
\hline & Cadastrados & 54 & 79,4 \\
\hline \multirow{3}{*}{$\begin{array}{l}\text { Frequência } \\
\text { das pescarias }\end{array}$} & 1 a 3 vezes/semana & 11 & 16,2 \\
\hline & 4 a 6 vezes/semana & 46 & 67,6 \\
\hline & Todos os dias & 11 & 16,2 \\
\hline \multirow{3}{*}{$\begin{array}{l}\text { Tipo de } \\
\text { embarcação }\end{array}$} & Canoa a remo (montaria) & 27 & 39,7 \\
\hline & $\begin{array}{l}\text { Canoa a motor, tipo } \\
\text { rabeta (batelão) }\end{array}$ & 40 & 58,9 \\
\hline & $\begin{array}{c}\text { Barco de } \\
\text { pequeno porte }\end{array}$ & 1 & 1,4 \\
\hline \multirow{5}{*}{$\begin{array}{l}\text { Renda mensal } \\
\text { (pesca)* }\end{array}$} & Até 1 salário mínimo & 37 & 54,4 \\
\hline & Até 2 salários mínimos & 24 & 35,2 \\
\hline & Até 3 salários mínimos & 2 & 3 \\
\hline & Até 4 salários mínimos & 2 & 3 \\
\hline & Não responderam & 3 & 4,4 \\
\hline
\end{tabular}


Tabela 2.

\begin{tabular}{|c|c|c|c|}
\hline & & \\
\hline & Variável & $n$ & $\%$ \\
\hline \multirow{3}{*}{$\begin{array}{c}\text { Atividade além } \\
\text { da pesca }\end{array}$} & Somente a pesca & 44 & 65 \\
\hline & Outras atividades*** & 20 & 30 \\
\hline & Bolsa Família & 4 & 5 \\
\hline \multirow{5}{*}{$\begin{array}{c}\text { Dependentes } \\
\text { da renda } \\
\text { mensal }\end{array}$} & 1 a 3 & 13 & 19 \\
\hline & 4 a 6 & 43 & 63,2 \\
\hline & 7 a 9 & 8 & 12 \\
\hline & 10 a 12 & 3 & 4,4 \\
\hline & 13 a 15 & 1 & 1,4 \\
\hline
\end{tabular}

Quanto à frequência das pescarias, 67,6\% afirmaram pescar de quatro a seis vezes por semana (Tabela 2), relatando também que as pescarias duravam normalmente um dia. Os principais locais de pesca citados foram o lago do Comprido, Sacaizal, região das Fazendas e rio Flexal. Sobre os tipos de embarcação, foram citados: canoa a remo, também chamada de 'montaria'; canoa com motor do tipo 'rabeta' (com 3,5 a 6,5 HP de propulsão), também conhecida como 'batelão'; e barco de pequeno porte com $12 \mathrm{HP}$ de propulsão do motor (Figuras 3A a 3C).

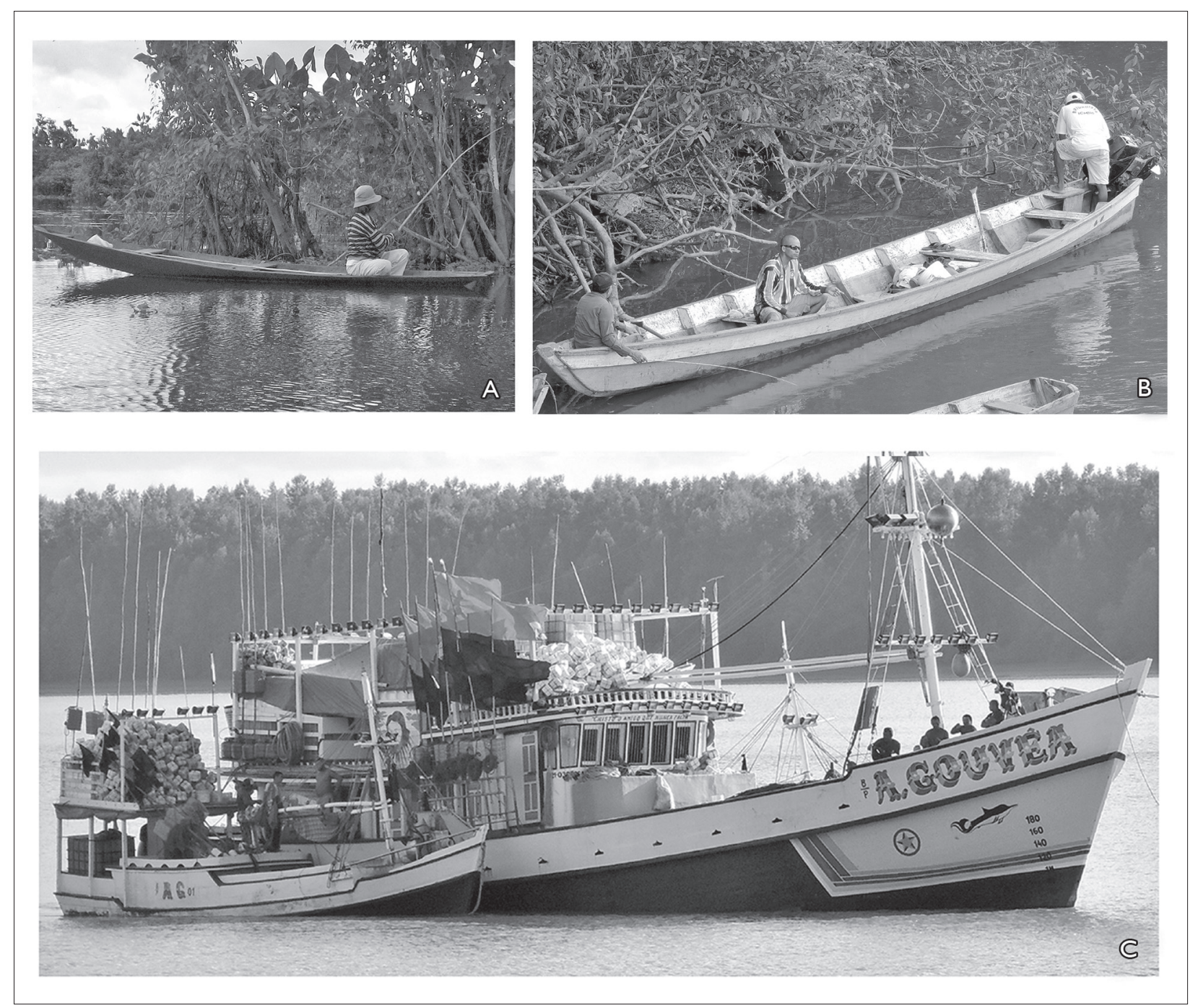

Figura 3. Embarcações típicas da região amazônica utilizadas pelos pescadores artesanais no município de Pracuúba: A) montaria; B) batelão; C) barco de pequeno porte. Fotos: (A) Rúbia Brandão; (B e C) Cesar Santos.

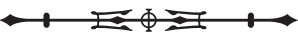


Entre os principais peixes capturados e comercializados, além do apaiari (Astronotus ocellatus), estão tucunaré (Cichla spp.), tamuatá ou 'tamatá' (Hoplosternum littorale), acará (Chaetobranchus spp.), aracu ou piau (Leporinus spp.), acari (Hypostomus sp.), piranha (Serrasalmus spp.), pacu (Myleus spp.), traíra (Hoplias malabaricus) e aruanã (Osteoglossum bicirrhosum). Quanto à comercialização, os pescadores relataram vender o pescado, in natura, principalmente ao atravessador, denominado por eles de 'geleiro', além de comercializarem o produto nas comunidades locais.

Em relação à renda mensal proveniente da atividade pesqueira, a maioria $(54,4 \%)$ relatou receber até um salário mínimo. Um percentual de 30\% dos pescadores trabalha em outras funções para complementar a renda, citadas como vaqueiro, servente, pedreiro, vigilante noturno, capinador e vendedor de açaí. A renda mensal referente a essas atividades é menor do que o salário mínimo. Além disso, alguns entrevistados disseram receber auxílio de programas sociais do governo federal, tal como o Bolsa Família.

Entre os entraves observados pelos pescadores em relação ao desenvolvimento da pesca no município de Pracuúba estão: a falta de uma fábrica de gelo operante; a falta de um caminhão frigorífico para auxílio na distribuição do pescado; e, principalmente, a falta de pavimentação da estrada, denominada por eles de 'ramal', a qual permite acesso à BR-156, rodovia que interliga o município de Pracuúba à capital Macapá.

\section{A PESCA DO APAIARI NA VISÃO DOS PESCADORES ARTESANAIS}

Todos os pescadores reconheceram o A. ocellatus mostrado na fotografia e, apesar de $80,9 \%$ o denominarem como apaiari, ele também foi reconhecido pela denominação de acará-açu, flamengo ou flamenguista. Quanto ao tipo de ambiente preferencial para captura da espécie, 91\% responderam que o apaiari é encontrado mais facilmente no meio da vegetação aquática, denominada por eles de barranco, mururé e aningal, que, na visão dos entrevistados, é o melhor local de alimentação para a espécie e esconderijo diante de predadores (Tabela 3).

Sobre o melhor período do ano para a captura do apaiari, 76,5\% dos pescadores relataram ser o verão (período de estiagem ou seca), pois é quando os peixes ficam concentrados nos locais onde o nível da água não reduziu totalmente. No entanto, 7,4\% afirmaram que capturam a espécie durante todo o ano, e que a eficiência na captura vai depender do método de pesca empregado, ou seja, do tipo de apetrecho utilizado (Tabela 3).

Tabela 3. Caracterização geral da pesca do apaiari. Legenda: $n=$ número de entrevistados.

\begin{tabular}{|c|c|c|c|}
\hline & Variável & $\mathrm{n}$ & $\%$ \\
\hline \multirow{3}{*}{$\begin{array}{l}\text { Nome vulgar } \\
\text { de } A \text {. ocellatus }\end{array}$} & Acará-açu & 11 & 16,1 \\
\hline & Flamengo ou flamenguista & 2 & 3 \\
\hline & Apaiari & 55 & 80,9 \\
\hline \multirow{2}{*}{$\begin{array}{l}\text { Habitat do } \\
\text { apaiari }\end{array}$} & Abaixo da vegetação aquática & 62 & 91 \\
\hline & Na margem (beira) do lago & 6 & 9 \\
\hline \multirow{3}{*}{$\begin{array}{l}\text { Melhor } \\
\text { período de } \\
\text { captura }\end{array}$} & Verão & 52 & 76,5 \\
\hline & Período chuvoso & 11 & 16,1 \\
\hline & $O$ ano todo & 5 & 7,4 \\
\hline \multirow{8}{*}{$\begin{array}{c}\text { Apetrechos } \\
\text { usados na } \\
\text { pesca do } \\
\text { apaiari }\end{array}$} & Rede & 21 & 30,9 \\
\hline & Caniço & 1 & 1,4 \\
\hline & Rede e caniço & 13 & 19,1 \\
\hline & Rede e linha de mão & 8 & 12 \\
\hline & Rede e zagaia & 7 & 10,2 \\
\hline & Rede, linha de mão e zagaia & 15 & 22 \\
\hline & $\begin{array}{l}\text { Rede, linha de mão, } \\
\text { zagaia e flecha }\end{array}$ & 2 & 3 \\
\hline & $\begin{array}{l}\text { Rede, linha de mão, } \\
\text { zagaia e tarrafa }\end{array}$ & 1 & 1,4 \\
\hline \multirow{3}{*}{$\begin{array}{c}\text { Tamanho } \\
\text { médio de } \\
\text { captura }(\mathrm{cm})\end{array}$} & $<20$ & 24 & 35 \\
\hline & 20 a 25 & 36 & 53 \\
\hline & $>25$ & 8 & 12 \\
\hline \multirow{3}{*}{ Conservação } & Caixa térmica de isopor e gelo & 63 & 92,7 \\
\hline & Freezer & 4 & 5,9 \\
\hline & Salga & 1 & 1,4 \\
\hline
\end{tabular}

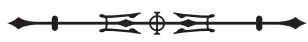


Quanto ao tamanho médio de captura do apaiari, eles relataram capturar peixes de 20 a $25 \mathrm{~cm}$. Em relação aos apetrechos utilizados na captura da espécie, $30,9 \%$ dos pescadores utilizam rede de emalhar; as malhas variam entre 8 e $11 \mathrm{~cm}$, entre nós opostos. De acordo com eles, as malhas de 8 e $9 \mathrm{~cm}$ entre nós opostos capturam peixes pequenos, denominados peixes miúdos, e as de 10 e $11 \mathrm{~cm}$ capturam os peixes maiores, denominados de peixes graúdos. A rede pode ser utilizada em combinação com outros apetrechos citados, como: linha de mão (linha de nylon com um anzol na extremidade); zagaia (semelhante a uma lança); caniço (composto por um fio de nylon, com um anzol na extremidade, interligado a uma haste de bambu); e flecha (Tabela 3). Porém, os pescadores observaram que, para a pesca tradicional e específica do apaiari, eles utilizam o caniço, com uso de iscas.

Dependendo do local de pescaria e da estratégia de pesca adotada, a quantidade de apaiari capturado pode variar de 10 a 50 kg; no verão, essa quantidade pode ser acima de $50 \mathrm{~kg}$. Sobre a fauna de peixes que acompanha a captura do apaiari, os pescadores citam principalmente: tucunaré (Cichla spp.), acará (Chaetobranchus spp.), traíra (Hoplias malabaricus), piranha (Serrasalmus spp.), aruanã (Osteoglossum bicirrhosum) e pacu (Myleus spp.).

Sobre a conservação do apaiari, é feita com a utilização de caixas térmicas de isopor, contendo gelo; sua comercialização é feita in natura ou apenas com o produto resfriado. O preço médio de comercialização do apaiari no município de Pracuúba é de $\mathrm{R} \$ 3,15$, sendo o menor preço registrado de $R \$ 1,50$ e o maior, de $R \$ 5,00$ por $\mathrm{kg}$. $O$ pagamento pelo peixe é feito à vista.

Quanto à preferência pelo apaiari, 100\% dos pescadores afirmaram que a espécie é muito procurada no município, sendo que eles próprios o apreciam para consumo. Em relação ao estoque natural deste pescado, os entrevistados consideram que está diminuindo e as possíveis causas enumeradas por eles como responsáveis por essa diminuição estão citadas na Tabela 4.
Tabela 4. Opinião dos pescadores sobre a diminuição do apaiari na região dos lagos de Pracuúba.

\begin{tabular}{c|c}
\hline Resposta & Justificativa \\
\hline \multirow{4}{*}{$\operatorname{sim}$} & "Tem muito pescador" \\
\cline { 2 - 2 } & "A população cresceu" \\
\cline { 2 - 2 } & "Matam a mãe e o pai, e os filhos ficam sem proteção" \\
\cline { 2 - 2 } & "Todo mundo pesca no lugar onde ele é encontrado" \\
\cline { 2 - 2 } & "Existem malhadeira e o búfalo" \\
\cline { 2 - 2 } & "Pesca com malha pequena pega os filhinhos" \\
\hline \multirow{3}{*}{ Não } & "Devido à pesca na piracema" \\
\cline { 2 - 2 } & "Porque o defeso proíbe a pesca" \\
\hline
\end{tabular}

\section{DISCUSSÃO}

\section{SOCIOECONOMIA DOS PESCADORES ARTESANAIS}

O resultado encontrado quanto à predominância do sexo masculino na atividade pesqueira foi observado durante os trabalhos de campo, onde havia maior participação dos homens na prática da pesca, enquanto as mulheres cuidavam das tarefas domésticas e/ou tinham outra ocupação fora de casa para complementar a renda familiar. Sendo assim, apesar de haver mulheres trabalhando como pescadoras em Pracuúba, essa prática é predominantemente masculina. Silva e Begossi (2004, p. 104) também encontraram a mesma organização entre homens e mulheres, ao investigarem sobre o uso dos recursos por ribeirinhos do médio rio Negro.

Alencar (1993, p. 66) e Fabré e Barthem (2005, p. 34) destacam que, embora as atividades executadas pelas mulheres nem sempre se desenvolvam nos mesmos espaços das atividades masculinas, e com a mesma frequência, a mulher possui uma relação orgânica com a pesca, pois desempenha certas funções que fazem parte dessa atividade, como consertos de materiais de trabalho, limpeza do pescado, conservação e comercialização.

Essa relação descrita por Alencar (1993, p. 66) e Fabré e Barthem (2005, p. 34) corrobora o observado em 
Pracuúba, já que as mulheres possuem papel fundamental na pesca, ajudando no trato e na venda do pescado, além de colaborarem no conserto de apetrechos. Ademais, elas desenvolvem outras atividades para ajudar na renda da família, atuando como merendeiras, em serviços gerais, faxineiras, geralmente desempenhando essas atividades nas escolas da sede ou nas escolas das comunidades e unidades básicas de saúde.

Quanto à naturalidade dos pescadores, apesar do predomínio de pessoas nascidas no município, há pessoas provenientes de outras cidades que chegaram à região em busca de melhores oportunidades de emprego. Como a cidade não possui empresas ou indústrias, mas apresenta uma extensa região formada por grandes lagos, a pesca tornou-se a oportunidade mais acessível aos novos habitantes, que, em sua maioria, buscaram legalizar-se como pescadores, cadastrando-se na colônia de pescadores.

Segundo Alves e Nishida (2003, p. 40), para a inclusão de uma população na categoria de comunidade tradicional, o tempo de permanência no local é um fator preponderante. Dessa forma, o alto tempo de fixação de residência observado entre os pescadores de Pracuúba, com média de 30 anos, evidencia a forte relação dos pescadores com o ambiente no qual vivem.

A despeito da baixa escolaridade constatada na pesquisa, o censo demográfico de 2010 identificou que 18,1\% da população deste município não é alfabetizada, entretanto, quando tal aspecto é relacionado à idade, esse percentual possui uma correlação positiva, pois em grupos de idade entre 24 e 59 anos o analfabetismo é de $13,9 \%$, e em grupos de 60 anos ou mais é de $30,2 \%$ (IBGE, 2010). De acordo com Alves e Nishida (2003, p. 41), entre os diversos fatores que causam o abandono das salas de aulas está a falta de escolas, a falta de incentivos para prosseguir os estudos e a necessidade de trabalhar para colaborar com a melhoria da renda da família, sendo este padrão também observado para o universo amostral deste estudo.
Lima et al. (2012, p. 77) verificaram, em duas comunidades ribeirinhas às margens do rio Madeira, que $66,6 \%$ dos pescadores possuíam apenas o ensino fundamental incompleto. Tamano et al. (2015, p. 702) também encontraram baixa escolaridade entre os pescadores de sururu da lagoa Mundaú, em Maceió, Alagoas. Segundo os autores, a justificativa para os poucos anos de estudo se deve à necessidade daquela população de trabalhar muito cedo para contribuir com a renda familiar.

Quando se fala do nível escolar dos jovens, é importante entender que estes, inicialmente, conciliam os estudos com a pesca para auxiliar os pais no sustento da casa, porém, com o passar do tempo, esta atividade torna-se sua ocupação principal (Maneschy, 1993, p. 46). A mesma autora observa ainda que, quando esses jovens confrontam as perspectivas longínquas de "melhorar de vida" através da obtenção de um diploma com a possibilidade imediata de ganhar seu próprio dinheiro todos os dias pescando, a última opção, na maioria das vezes, prevalece e acontece o abandono prematuro da escola como resultado. Este fato é observado no presente estudo em relação ao município de Pracuúba, havendo relação com a estrutura familiar, pois a maioria dos pescadores tem uma companheira ou, no caso das pescadoras, um companheiro, com os quais tem filhos.

Maneschy (1993, p. 46) ressalta que as uniões conjugais nas comunidades tradicionais ocorrem muito cedo, por volta dos 17 a 20 anos de idade para os homens e dos 16 para as mulheres, que logo engravidam dos primeiros filhos. Assim, esses jovens trocam o banco da escola pelo banco da canoa, dada a responsabilidade de sustentar os filhos.

No que concerne à moradia, além de ser o local onde a família reside, a casa também é o espaço no qual o pescado é comercializado. Os atravessadores conhecem os pescadores e vão até eles efetuar a compra. Além disso, é na residência que o pescador guarda e conserta suas redes e faz a manutenção de todo o aparato utilizado na pesca.

A falta de saneamento básico obriga a população a descartar os dejetos nos lagos, causando eutrofização desses ambientes, além de contaminação do lençol freático, 
devido às fossas escavadas nos quintais, com a finalidade de descartar parte desses rejeitos. Assim como na comunidade estudada, Alves da Silva et al. (2009, p. 540), ao investigarem pescadores artesanais no Reservatório de Billings, em São Paulo, observaram a precariedade do saneamento básico naquelas comunidades, com $87,8 \%$ das residências descartando seus rejeitos em fossas. Tamano et al. (2015, p. 704) também relataram que $61,54 \%$ dos pescadores de sururu da lagoa Mundaú não têm acesso à rede de esgoto, descartando parte de seus resíduos na própria lagoa.

No que se refere à prática da pesca artesanal, todos os entrevistados se declararam pescadores artesanais. Misund et al. (2002, p. 25) afirmam que a pesca artesanal se caracteriza por ocorrer em pequena escala, com o uso de embarcações menores, com pouco ou nenhum gasto de combustível, tendo uma extraordinária variedade de métodos de captura desenvolvidos de acordo com os diferentes recursos, ambientes e estações. Segundo os mesmos autores, entre os diversos equipamentos característicos da pesca artesanal, há o uso de canoas, jangadas, pequenas embarcações a motor, lanças, arpões, redes de emalhar, puçás, redes de cerco, linha de mão, anzol.

A pesca tem um papel fundamental na organização social das comunidades, pois é a principal fonte de alimento e de renda das populações tradicionais que vivem às margens de rios e lagos. Segundo Diegues (2000, p. 49), a pesca artesanal é predominantemente familiar, com a tripulação constituída por membros da família, por conhecidos ou parentes, sendo que o produto resultante dessa pequena pesca é, em sua maioria, consumido pela família e o excedente, comercializado. Portanto, a pesca no município de Pracuúba é marcada pelo uso da mão de obra familiar e pelo conhecimento tradicional acumulado e repassado ao longo de gerações (Diegues, 2004, p. 122), o que a caracteriza como artesanal.

Sendo assim, a maioria dos pescadores do município não sai sozinha para pescar, mas em sistema de parceria com outros pescadores que pertencem ao seu ciclo familiar ou com amigos próximos. Dâmaso (2006, p. 51) teve a mesma percepção em Itacaré, Bahia, onde as pescarias são realizadas, geralmente, por dois homens, podendo haver embarcações com um ou três pescadores. Segundo a mesma autora, o sistema de parceria adotado envolve relacionamentos e ligações específicas de parentesco e amizade, e o produto é dividido entre eles.

Considerando a organização desses pescadores, observou-se que a maioria está articulada na Colônia de pescadores Z-11, mas um número significativo ainda não está associado. Segundo os próprios pescadores, há dificuldade em se associar, devido a uma extensa documentação exigida pela colônia e também porque eles não veem benefícios diretos nisso, pois, de acordo com a percepção deles, apenas um grupo seleto se favorece dos recursos destinados a essa instituição.

Fabré e Barthem (2005, p. 35) verificaram que a maioria dos pescadores de bagres do eixo SolimõesAmazonas não está filiada a seus órgãos de classe. Esse é um dado preocupante, pois a colônia é uma forma de associativismo importante para as comunidades tradicionais, já que representa a 'voz' dos pescadores perante as instituições públicas.

De acordo com Silva (2005, p. 71), qualquer forma de organização política, além de estar estabelecida jurídica e socialmente, deve ter prestígio perante a sociedade na qual se insere, uma vez que, institucionalmente, essa organização atua diretamente na tomada de decisão em benefício próprio, de seus membros e de toda a comunidade. Além disso, a opinião emitida por este grupo tem grande importância na definição de políticas públicas voltadas para a sua área de atuação.

No que tange às pescarias, as viagens dos pescadores geralmente são curtas; eles vão e voltam no mesmo dia, pois os locais de pesca ficam próximos. Geralmente, as pescarias ocorrem de segunda a sexta-feira. A maioria reserva os finais de semana para consertar as redes de pesca, cuidar dos afazeres da casa e descansar. Isaac et al. (1998, p. 27), ao descreverem a pesca nos lagos do estado do Amapá, também constataram que as viagens são curtas,

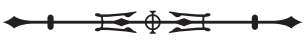


estendendo-se, no máximo, por um ou dois dias. Outro fator que influencia na ida e vinda das pescarias no mesmo dia são os problemas com a precária disponibilidade de gelo no município, pois o pescador não leva gelo na embarcação, tendo que retornar à sua residência ao final do dia para repassar parte do pescado ao atravessador e destinar a outra ao consumo e à comercialização local.

As embarcações e as artes de pesca empregadas nesta atividade em lagos são típicas da pesca tradicional. Santos (2005, p. 71), no estudo sobre a cadeia produtiva da pesca artesanal no estado do Pará, identificou que 51\% dos pescadores do nordeste do Estado utilizam, para a execução de seu trabalho, barcos a motor e 49\%, canoas a remo. Quanto às artes de pesca empregadas, o autor identificou que $56 \%$ utilizam redes de diferentes malhas para a captura do pescado. Contudo, é importante ressaltar que, apesar de certa modernização, as metodologias para a prática da pesca nas diversas comunidades pesqueiras da Amazônia ainda conservam os modos tradicionais.

No que concerne aos peixes pescados e comercializados no município de Pracuúba, Isaac et al. (1998, p. 27) também identificaram as mesmas espécies para essa região, tais como apaiari, tucunaré, traíra, tamuatá, aruanã, piranha, entre outras. Esse pescado é vendido ao atravessador ('geleiro').

O 'geleiro' é chamado por esse nome porque transporta o gelo para conservação do pescado em sua caminhonete, já que muitos pescadores não possuem freezer e, por isso, não conseguem produzir gelo suficiente. Em troca, o atravessador exige exclusividade e compra o produto por um valor muito abaixo do praticado pelo mercado, revendendo a um preço muito maior na capital Macapá e em outras cidades do estado do Amapá. O trabalho de Silva e Dias (2010, p. 51) corrobora o presente estudo. Os autores relatam que o pescado vendido em Macapá torna-se mais caro por chegar à capital por intermédio de atravessadores.

Em razão de Pracuúba ter uma fábrica de gelo desativada, que não oferece o produto para a conservação do pescado, por não possuir caminhão frigorífico para o seu transporte para outras cidades do estado do Amapá e pelo difícil acesso à BR-156, o 'geleiro' assume um papel importante na distribuição e na venda desse pescado.

Em relação ao rendimento financeiro proveniente da pesca, a renda da maioria dos entrevistados (renda de até um salário mínimo) está em concordância com a relatada pelo censo de 2010 para famílias do município, no valor de $R \$ 256,00$ (IBGE, 2010). A maioria dos pescadores entrevistados tem na pesca artesanal, realizada diariamente, sua principal fonte de renda e subsistência.

Isaac et al. (1998, p. 42) ressaltam que a pesca no estado do Amapá apresenta dois extremos econômicos: de um lado, encontra-se uma minoria de empresas que compra o pescado das embarcações de maior porte, a um baixo valor de mercado, e revendem esse pescado para fora do Estado e para o exterior, tendo uma margem de lucro muito elevada; de outro lado, existe um grande número de pescadores artesanais, cujas embarcações rudimentares e com baixa capacidade pesqueira geram lucros muito baixos, que não se revertem em benefícios econômicos para o Estado e nem para os próprios pescadores e seus familiares, resultando em baixa qualidade de vida dessas populações.

\section{A PESCA DO APAIARI NA VISÃO DOS PESCADORES ARTESANAIS}

O apaiari é um peixe muito consumido no município de Pracuúba. Isaac et al. (1998, p. 27) citam essa espécie como uma das mais pescadas na região dos lagos, juntamente com o tucunaré. Fontenele e Nepomuceno (1983, p. 88) enfatizam que se trata de uma espécie bastante apreciada no Norte e no Nordeste do Brasil, por apresentar carne saborosa, firme e sem espinhas intramusculares. Por ser preferencial na alimentação da população do município, é facilmente identificada pelos pescadores.

Silvano (2004, p. 192) afirma que os pescadores artesanais apresentam conhecimento aprofundado acerca dos recursos dos quais dependem. Dessa forma, a facilidade 
apontada pela maioria dos entrevistados quanto à pesca do apaiari evidencia o conhecimento detalhado que estes pescadores têm da biologia e da ecologia da espécie. Thé (2003, p. 17) ressalta que a compreensão dos pescadores sobre a ocupação e a movimentação dos peixes no ambiente aquático contribui com a pesca, tornando-a mais eficiente.

Os pescadores do município de Pracuúba distinguem duas épocas do ano, o período chuvoso (inverno), que vai de janeiro a abril, e o seco (verão), que se estende de setembro a dezembro, assim como descrito por Fisch et al. (1998, p. 104) e Ananias et al. (2010, p. 219) para a região amazônica. De acordo com os entrevistados, as pescarias são fartas no verão, pois os peixes ficam concentrados em regiões permanentemente inundadas.

Contrariamente, no inverno, os peixes se dispersam por longas distâncias, já que o lago está cheio, facilitando a sua locomoção e tornando mais difícil a busca por este recurso pesqueiro. Em função da vegetação e da ampliação das áreas de distribuição das espécies, resultados de Isaac e Barthem (1995, p. 298) corroboram a afirmação e informam que os rios de água branca da Amazônia, especialmente as áreas inundáveis, são regiões de alta produtividade, onde a pesca é intensa, principalmente no período de estiagem, quando os peixes ficam concentrados no canal permanente, porque as águas estão baixas e as margens estão secas. $\mathrm{Na}$ visão dos pescadores de Pracuúba, essa sazonalidade exerce grande influência na pesca do apaiari. Quanto aos apetrechos utilizados na pesca desta espécie em Pracuúba, os pescadores utilizam artes de pesca artesanais, assim como as populações ribeirinhas do rio Negro, que empregam diferentes artes, de acordo com os objetivos da pesca, incluindo subsistência ou comercialização, tipo e sazonalidade dos recursos explorados (Silva; Begossi, 2004, p. 109). Na pesca do apaiari, vários pescadores afirmaram que no verão o uso da rede é o melhor método, e no inverno o caniço é o mais eficiente. Dessa forma, as estratégias e apetrechos de pesca expressam uma adaptabilidade às variações sazonais do nível das águas, impostas pelo ciclo das chuvas (Batista et al., 2004, p. 80).
A pesca do apaiari realizada com o uso de rede de emalhar, com malhas variando de 8 a $11 \mathrm{~cm}$ entre nós opostos, segundo informações dos pescadores de Pracuúba, captura outros peixes, como tucunaré, acará, aruanã, tamuatá, indicando que essas espécies compartilham o mesmo habitat. Santos et al. (1984, p. 44) afirmam que essas espécies vivem em ambientes lênticos, áreas marginais cobertas por vegetação e dispostas em lagos.

A pesca tradicional do apaiari é feita com o caniço e se dá próxima à vegetação e a barrancos, ocorrendo da seguinte forma: antes de jogar o caniço na água, o pescador escuta onde o peixe está comendo; quando ele localiza a área, joga o caniço, usando iscas como o sarará e o camarão, itens que fazem parte da alimentação desse peixe. Outra estratégia do pescador é dar pequenas batidas na água com os dedos e com a ponta do caniço, simulando o som de peixe comendo. Este tipo de som chama a atenção de $A$. ocellatus, que se desloca em direção à área onde o pescador está.

Em estudo na Usina Hidrelétrica de Tucuruí, Pará, Alves e Barthem (2008, p. 555) analisaram a pesca tradicional do tucunaré e verificaram que nesta prática também se utiliza o caniço e a isca viva, como o camarão e a piaba, itens que fazem parte da alimentação daquele peixe. Essa pesca consiste em identificar os locais de alimentação e de reprodução dessa espécie que se tornam fixos no lago, chamados de coito. A prática ocorre nas águas rasas nas margens do lago ou em áreas onde há galhadas de árvores mortas submersas no lago. Trata-se de um tipo de pesca que se assemelha muito à captura do apaiari realizada pelos pescadores artesanais de Pracuúba.

Em relação à diminuição dos estoques do apaiari e das demais espécies ícticas, pode-se dizer que se deve não apenas à pesca extrativa predatória, mas à criação de búfalos por fazendeiros da região. Diegues (2002, p. 165) afirma que, entre os impactos negativos das atividades humanas para a região da costa amazônica do Amapá, a pecuária bubalina extensiva é a grande responsável pela compactação do solo, o que é prejudicial para a biodiversidade.

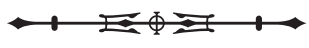




\section{CONSIDERAÇÕES FINAIS}

O município de Pracuúba, apesar de ser uma das principais regiões produtoras de pescado advindo da pesca feito no interior do estado do Amapá, não oferece infraestrutura suficiente para a conservação e a distribuição do produto. A falta de uma fábrica de gelo, as condições precárias do ramal que interliga a sede municipal com a BR-156, que dá acesso à capital Macapá e aos demais municípios, além da falta de um caminhão frigorífico que faça essa distribuição, bem como de uma associação consolidada, que defenda os direitos e o interesse dos pescadores artesanais, são grandes entraves ao desenvolvimento da pesca na região dos lagos.

A vida da comunidade local e a economia da região giram em torno da pesca, por isso medidas mitigadoras devem ser tomadas pelas autoridades competentes, com o intuito de resolver os obstáculos a esta atividade nesse município, principalmente buscando desenvolver ações voltadas para a melhoria das condições de trabalho e aumento da renda desses pescadores.

Os dados socioeconômicos associados ao conhecimento etnoecológico acumulado e repassado ao longo de gerações podem ser uma importante ferramenta no desenvolvimento de medidas sustentáveis e na cogestão dos recursos pesqueiros da região dos lagos de Pracuúba (parceria entre poder público e comunidade local), resultando não apenas na preservação da biodiversidade, mas em melhorias socioeconômicas e na manutenção da pesca artesanal dessa região.

\section{REFERÊNCIAS}

ALENCAR, Edna. Gênero e trabalho nas sociedades pesqueiras. In: FURTADO, Lourdes; LEITÃO, Wilma; MELLO, Alex Fiuza de (Org.). Povos das águas: realidade e perspectivas na Amazônia. Belém: Museu Paraense Emílio Goeldi, 1993. p. 63-81.

ALVES, Marília Cunha Botelho; BARTHEM, Ronaldo Borges. A pesca comercial dos "tucunarés" Cichla spp. (Perciformes, Cichlidae) no reservatório da UHE-Tucuruí, rio Tocantins, PA. Boletim do Instituto de Pesca, São Paulo, v. 34, n. 4, p. 553-561, 2008. Disponível em: <ftp://ftp.sp.gov.br/ftppesca/34_4_553-561. pdf $>$. Acesso em: 17 mar. 2012.
ALVES, Rômulo Romeu da Nóbrega; NISHIDA, Alberto Kioharu. Aspectos socioeconômicos e percepção ambiental dos catadores de caranguejo-uçá Ucides cordatus cordatus (L. 1763) (Decapoda, Brachyura) do estuário do rio Mamangupé, Nordeste do Brasil. Interciencia, Venezuela, v. 28, n. 1, p. 36-43, jan. 2003. Disponível em: <http://www.redalyc.org/articulo.oa?id=33907606>. Acesso em: 16 mar. 2012

ALVES DA SILVA, Maria Eugênia Porto; CASTRO, Paula Maria Gênova de; MARUYAMA, Lidia Sumile; PAIVA, Patrícia de. Levantamento da pesca e perfil socioeconômico dos pescadores artesanais profissionais no reservatório Billings. Boletim Instituto de Pesca, São Paulo, v. 35, n. 4, p. 531-543, 2009. Disponível em: <ftp://ftp.sp.gov.br/ftppesca/35_4_531-543.pdf>. Acesso em: 17 mar. 2012.

ANANIAS, Daniela dos Santos; SOUZA, Everaldo Barreiros de; SOUZA, Paulo Fernando; SOUZA, Adriano Marlisom Leão de; VITORINO, Maria Isabel; TEIXEIRA, Gleyciano Mendes; FERREIRA, Douglas Batista da Silva. Climatologia da estrutura vertical da atmosfera em novembro para Belém-PA. Revista Brasileira de Meteorologia, São Paulo, v. 25, n. 2, p. 218-226, jun. 2010. Disponível em: <http://www.scielo.br/ pdf/rbmet/v25n2/a06v25n2.pdf>. Acesso em: 18 jun. 2014.

BAILEY, Kenneth D. Methods of social research. 2. ed. New York: The Free Press/Macmillan Publishers, 1982.

BARTHEM, R. B.; FABRÉ, N. N. Biologia e diversidade dos recursos pesqueiros da Amazônia. In: RUFFINO, M. L. (Coord.). A pesca e os recursos pesqueiros na Amazônia brasileira. Manaus: ProVárzea/ IBAMA, 2004. p. 17-62.

BATISTA, Vandick da Silva; ISAAC, Victoria Judith; VIANA, João Paulo. Exploração e manejo dos recursos pesqueiros da Amazônia. In: RUFFINO, M. L. (Coord.). A pesca e os recursos pesqueiros na Amazônia brasileira. Manaus: ProVárzea/IBAMA, 2004. p. 63-152.

BEGOSSI, Alpina. Small-scale fisheries in Latin America: management models and challenges. MAST, v. 9, n. 2, p. 7-31, 2010.

BERKES, Fikret; COLDING, Johan; FOLKE, Carl. Rediscovery of traditional ecological knowledge as adaptive management. Ecological Applications, Washington, v. 10, n. 5, p. 1251-1262, out. 2000.

DÂMASO, Renata Cristina da Silva Costa. Etnoecologia dos pescadores de Itacaré, Bahia, Brasil. 2006. 95 f. Dissertação (Mestrado em Zoologia) - Universidade Estadual de Santa Cruz, Ilhéus, 2006.

DIEGUES, Antônio Carlos. A pesca construindo sociedades. São Paulo: NUPAUB/USP, 2004.

DIEGUES, Antônio Carlos. Povos e águas: inventário de áreas úmidas brasileiras. 2. ed. São Paulo: NUPAUB/USP, 2002.

DIEGUES, Antônio Carlos (Org.). Os saberes tradicionais e a biodiversidade no Brasil. São Paulo: MMA/COBIO/NUPAUB/ USP, 2000. 211 p. 
FABRÉ, Nídia Noemi; BARTHEM, Ronaldo Borges (Coord.). O manejo da pesca dos grandes bagres migradores: piramutaba e dourada no eixo Solimões-Amazonas. Manaus: ProVárzea, IBAMA, 2005. Disponível em: <http://philip.inpa.gov.br/publ livres/Dossie/Mad/Outros\%20documentos/38._DT_EE_Bagres. pdf > . Acesso em: 24 out. 2010.

FISCH, Gilberto; MARENGO, José A.; NOBRE, Carlos A. Uma revisão geral sobre o clima da Amazônia. Acta Amazonica, Manaus, v. 28, n. 2, p. 101-126, 1998.

FONTENELE, Osmar; NEPOMUCENO, Francisco Hilton. Exame dos resultados da introdução do apaiari, Astronotus ocellatus (Agassiz, 1849), em açudes do Nordeste do Brasil. Boletim Técnico do DNOCS, Fortaleza, v. 41, n. 1, p. 85-99, 1983.

FREITAS, Carlos Edwar de Carvalho; RIVAS, Alexandre Almir Ferreira. A pesca e os recursos pesqueiros na Amazônia Central. Ciência e Cultura, Campinas, v. 58, n. 3, p. 30-32, jul./set. 2006.

INOMATA, Sandrelly Oliveira; FREITAS, Carlos Edwar de Carvalho. A pesca comercial no médio rio Negro: aspectos econômicos e estrutura operacional. Boletim do Instituto de Pesca, São Paulo, v. 41, n. 1, p. 79-87, 2015.

INSTITUTO BRASILEIRO DE GEOGRAFIA E ESTATÍSTICA (IBGE). Censo Demográfico 2010. Rio de Janeiro: IBGE, 2010. Disponível em: <http://www.ibge.gov.br/home/estatistica/ populacao/censo2010/>. Acesso em: 20 jan. 2012.

INSTITUTO BRASILEIRO DE MEIO AMBIENTE E DOS RECURSOS NATURAIS RENOVÁVEIS (IBAMA). Estatística da pesca 2007. Brasil. Grandes Regiões e Unidades da Federação. Brasília: IBAMA, 2007. 113 p.

ISAAC, Victoria Judith; ARAUJO, Ana Rosa; SANTANA, João Vicente. A pesca no estado de Amapá: alternativas para o seu desenvolvimento sustentável. Macapá: Secretaria de Estado de Meio Ambiente, Governo do Estado do Amapá, 1998. 132 p. (Série Estudos do Amapá, v. 1).

ISAAC, Victoria Judith; BARTHEM, Ronaldo B. Os recursos pesqueiros da Amazônia brasileira. Boletim do Museu Paraense Emilio Goeldi, série Antropologia, Belém, v. 1, n. 2, p. 295 339, 1995. Disponível em: <http://repositorio.museu-goeldi. br: 8080/jspui/bitstream/123456789/550/1/B\%20MPEG\%20 Ant\%2011(2)\%201995\%20Isaac.pdf>. Acesso em: 17 mar. 2012.

LIMA, Maria Alice Leite; DORIA, Carolina Rodrigues da Costa; FREITAS, Carlos Edwar de Carvalho. Pescarias artesanais em comunidades ribeirinhas na Amazônia brasileira: perfil socioeconômico, conflitos e cenário da atividade. Ambiente \& Sociedade, São Paulo, v. 15, n. 2, p. 73-90, maio/ago. 2012. Disponível em: <http://www.scielo.br/pdf/asoc/v15n2/05.pdf>. Acesso em: 20 mar. 2015.
MANESCHY, Maria Cristina. Pescadores nos manguezais: estratégias, técnicas e relações sociais de produção na captura de caranguejo. In: FURTADO, Lourdes; LEITÃO, Wilma; MELLO, Alex Fiuza de (Org.). Povos das águas: realidade e perspectivas na Amazônia. Belém: Museu Paraense Emílio Goeldi, 1993. p. 19-62.

MÉRONA, Bernard de. Pesca e ecologia dos recursos aquáticos na Amazônia. In: FURTADO, Lourdes; LEITÃO, Wilma; MELLO, Alex Fiuza de (Org.). Povos das águas: realidade e perspectivas na Amazônia. Belém: Museu Paraense Emílio Goeldi, 1993. p. 159-185.

MINISTÉRIO DA PESCA E AQUICULTURA (MPA). Boletim estatístico da pesca e aquicultura 2011. Brasília: MPA, 2011. 60 p.

MINISTÉRIO DA PESCA E AQUICULTURA (MPA). Boletim estatístico da pesca e aquicultura 2010. Brasília: MPA, 2010. $128 \mathrm{p.}$

MISUND, Ole Arve; KOLDING, Jeppe; FRÉON, Pierre. Fish capture devices in industrial and artisanal fisheries and their influence on management. In: HART, Paul J. B.; REYNOLDS, John D. (Ed.). Handbook of fish biology and fisheries. Malden: Blackwell, 2002. p. 13-36. v. 2.

RABELO, Benedito Vitor; PINTO, Adalberto do Carmo; SIMAS, Alandy Patrícia; TARDIN, Antônio Tebaldi; FERNANDES, Aristóteles Viana; SOUZA, César Bernardo de; MONTEIRO, Elenilza Maria P. Bentes; FACUNDES, Francinete da Silva; ÁVILA, José Elias de Souza; SOUZA, Josiane S. Aguiar de; GUEDES, Luiz Alberto Costa; PENHA, Otizete A. de Alencar da; MELO, Rosa Maria de Sousa; GIBSON, Valdeci Marques (Ed.). Macrodiagnóstico do estado do Amapá: primeira aproximação do zoneamento ecológico econômico. 2. ed. Macapá: IEPA, 2006.

RAMIRES, Milena; CLAUZET, Mariana; ROTUNDO, Matheus Marcos; BEGOSSI, Alpina. A pesca e os pescadores artesanais de Ilhabela (SP), Brasil. Boletim do Instituto de Pesca, São Paulo, v. 38, n. 3, p. 231-246, 2012.

SANTOS, Geraldo Mendes dos; SANTOS, Ana Carolina Mendes dos. Sustentabilidade da pesca na Amazônia. Estudos Avançados, São Paulo, v. 19, n. 54, p. 165-182, 2005. Disponível em: < http:// www.scielo.br/pdf/ea/v19n54/09.pdf> . Acesso em: 23 mar. 2015.

SANTOS, Geraldo Mendes dos; JEGU, Michel; MERONA, Bernard de. Catálogo de peixes comerciais do baixo rio Tocantins: Projeto Tucuruí. Manaus: ELETRONORTE/CNPq/INPA, 1984. $83 \mathrm{p.}$

SANTOS, Marcos Antônio Souza dos. A cadeia produtiva da pesca artesanal no estado do Pará: estudo de caso no nordeste paraense. Revista Amazônia Ciência e Desenvolvimento, Belém, v. 1, n. 1, p. 61-81, jul./dez. 2005. Disponível em: < http://www. bancoamazonia. com.br/images/arquivos/institucional/biblioteca/revista_amazonia/ edicao01/061a082.pdf> . Acesso em: 16 mar. 2012.

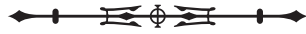


SILVA, Andréa Leme da; BEGOSSI, Alpina. Uso dos recursos por ribeirinhos do médio Rio Negro. In: BEGOSSI, Alpina (Org.). Ecologia de pescadores da Mata Atlântica e da Amazônia. São Paulo: HUCITEC, NEPAM/UNICAMP, NUPAUB/USP, FAPESP, 2004. p. 89-148.

SILVA, Antonio Esmerahdson de Pinho da. A organização social da colônia de pescadores de Imperatriz Zona 29 (CPI Z-29), estado do Maranhão. 2005. 98 f. Dissertação (Mestrado em Planejamento do Desenvolvimento) - Universidade Federal do Pará, Belém, 2005.

SILVA, Luis Mauricio Abdon da; DIAS, Marcos Tavares. A pesca artesanal no estado do Amapá: estado atual e desafios. Boletim Técnico-Científico do CEPNOR, Belém, v. 10, n. 1, p. 43-53, 2010.

SILVA, Luis Mauricio Abdon da; SILVA, Sirley Luzia de Figueiredo. A atividade pesqueira na região atlântica da costa do Amapá: município de Amapá, Pracuúba, Tartarugalzinho e baixo Araguari. In: COSTANETO, Salustiano Vilar da (Org.). Inventário biológico das áreas do Sucuriju e região dos lagos, no Amapá. Macapá: IEPA, 2006. p. 173-187.
SILVANO, Renato Azevedo Matias. Pesca artesanal e etnoictiologia. In: BEGOSSI, Alpina (Org.). Ecologia de pescadores da Mata Atlântica e da Amazônia. São Paulo: HUCITEC, NEPAM/ UNICAMP, NUPAUB/USP, FAPESP, 2004. p. 187-222.

TAMANO, Luana Tieko Omena; ARAUJO, Daniel de Magalhães; LIMA, Beethoven Brandão Correia de; SILVA, Francisca Noelma Freitas da; SILVA, Joseane da. Socioeconomia e saúde dos pescadores de Mytella falcata da Lagoa Mundaú, Maceió-AL. Boletim do Museu Paraense Emílio Goeldi. Ciências Humanas, Belém, v. 10, n. 3, p. 699-710, set./dez. 2015. Disponível em: $<$ http://dx.doi.org/10.1590/1981-81222015000300011>. Acesso em: 20 mar. 2015.

THÉ, Ana Paula Glinfskoi. O conhecimento ecológico, regras de uso e manejo local dos recursos naturais na pesca do alto-médio São Francisco, MG. 2003. 213 f. Tese (Doutorado em Ecologia e Recursos Naturais) - Universidade Federal de São Carlos, São Carlos, 2003. 